\title{
Foreign Objects: Architectural History in the Age of Globalization
}

DAVID SALOMON

Ithaca College
This paper addresses the theme of global and disglobal networks via the lens of architectural history, pedagogy and historiography. Specifically, it will argue that as currently defined in the United States the teaching of global architectural history is in danger of 1) losing its focus on architectural objects, and 2) of repeating the very gentrifying effects associated with globalization that it seeks to overcome. In what follows I will propose a mode of architectural history that avoids these traps by focusing first on architectural forms and types. Clorinda Testa's design of the Bank of London and South America in Buenos Aires, Argentina will be used to test this theory. Before examining that object, we must first examine the historiographical context that makes it a relevant case study.

\section{HISTORY GLOBALIZED}

For over a decade architectural history has been subjected to the forces of globalization. Within professional schools of architecture in the U.S. a global perspective on architecture is now a legally binding condition. According to the current (2014) guidelines issued by the National Architectural Accreditation Board (NAAB) - the body that grants institutions the right to offer professional architectural degrees - the role of architectural history within a curriculum is to have students

"... understand the parallel and divergent histories of architecture and the cultural norms of a variety of indigenous, vernacular, local, and regional settings in terms of their political, economic, social, ecological, and technological factors."

The implied emphasis on everyday examples suggests that this is an attempt to correct the Western/Northern/fully industrialized bias of the traditional canon.

Canonization is such a charged subject that it has been abandoned as an organizing idea from the NAAB guidelines. In the previous version of the NAAB requirements from 2009, under the heading Historical Traditions and Global Culture, the goal of history was to produce an:
"Understanding of parallel and divergent canons and traditions of architecture, landscape and urban design including examples of indigenous, vernacular, local, regional, national settings from the Eastern, Western, Northern, and Southern hemispheres in terms of their climatic, ecological, technological, socioeconomic, public health, and cultural factors." ${ }^{2}$

The underlined terms above are the ones taken out in the next version. In 2014 the language, and intention, has changed. Canons and traditions have been replaced by histories; "design" was removed; "nations" was removed; "climate" was removed, the different hemispheres were removed.

The shift from "canon" and "tradition" to "histories" suggests that the function of history is to provide the context for architectural form not to explain architectural objects. This implies that a project's inclusion in architectural history is not dependent on any aesthetic standard associated with the traditional canon. Rather, its relevance is based on its ability to accurately illustrate a culture or region at the time a building, landscape or city was conceived of or built.

As outlined in the Accreditation Guidelines the logic of architectural form is a discrete area of inquiry. The task of understanding the morphology of architectural form is covered in the parameters for "ordering systems," and "use of precedent," which requires the "ability" to comprehend and effectively "use" the "fundamental principles" found in architectural artifacts. In other words, the role of architectural history is to deliver social, not stylistic knowledge.

\section{OLD MODELS}

Textbooks like A Global History of Architecture (Ching, Jarzombek and Prakash) were created to directly address this requirement. ${ }^{3}$ Its inclusive, chronological, and encyclopedic organization forgoes the conventional and too often triumphant narratives associated with the textbooks of the past. In fact, it almost eliminates narrative altogether. If there is a story it is of globalization itself, a story about the exchange of seemingly equivalent ideas and objects without regard to previous borders or hierarchies. In doing so it expands the canon to the point of breaking it.

To address this narrative gap, two of the authors of A Global History of Architecture (Mark Jarzombek and Vikram Prakash) have founded 


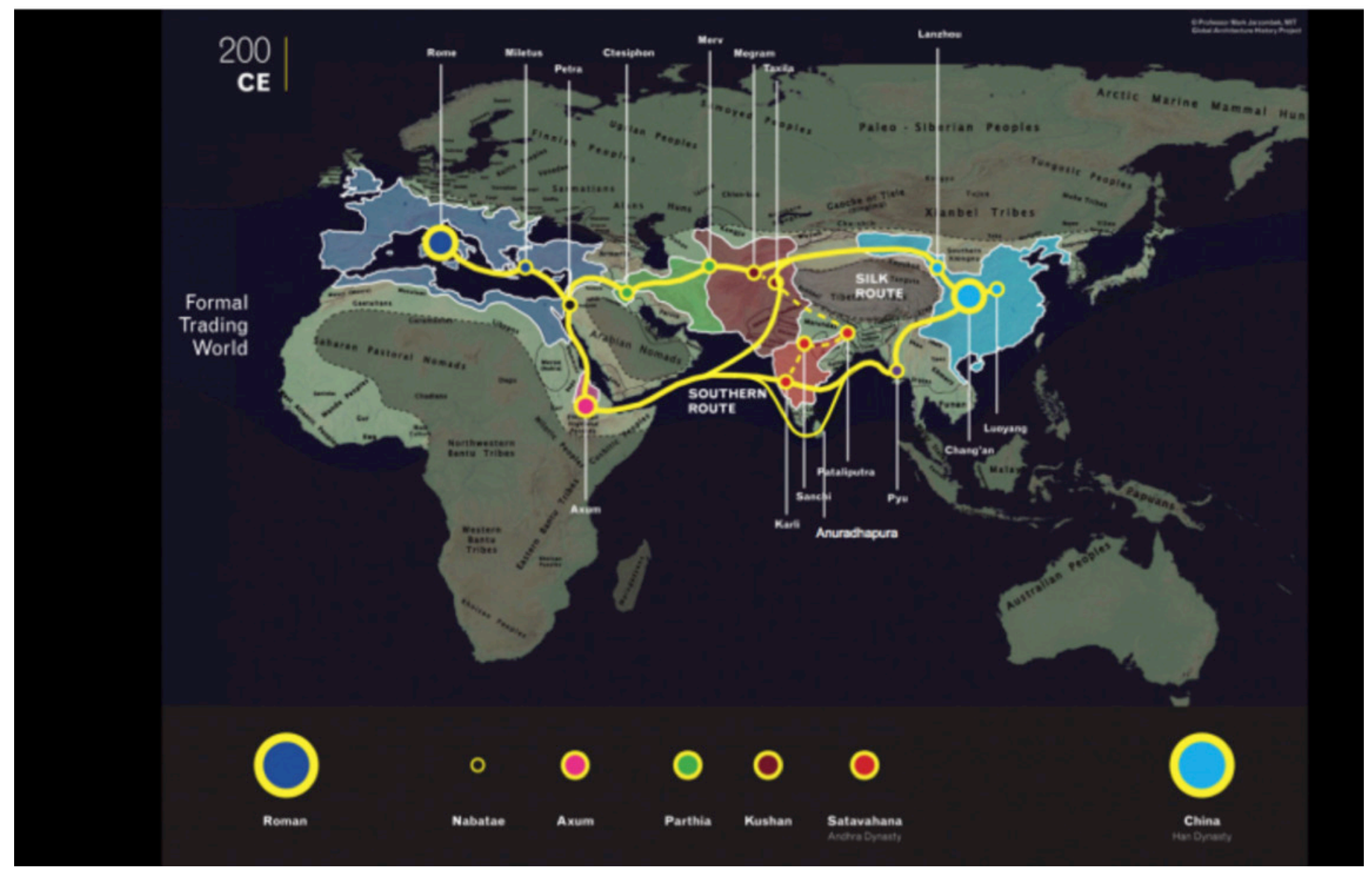

Figure 1: Map of the Formal Trading World, c. 200CE, from the Global Architectural History Teaching Collaborative website.

the Global Architectural History Teaching Collaborative. Its members are currently preparing lecture materials (i.e. slide shows plus lecture scripts or outlines) to share with one another. So far one narrative has emerged that links the diverse architectures to be presented to students: the story of cultural interaction, migration and exchange.

Among other devices, the preponderance of trade route maps found in the Global History of Architecture book and in GAHTC's soon-tobe-online materials illustrates this emphasis, as they diagram routes of economic, military and cultural connection. Placing these "local and regional" objects within the recognizable narrative of economic and intellectual exchange - and the unequal power games inherent to them - the unstated but clear message is that 'this is what humans do; they expand their knowledge and their influence via networks of communication and trade.' Globalization (after imperialism and colonialism) is just the latest version of this practice.

In this scenario the task for teachers of architectural history is to find examples that show how and when vast transportation and communication systems have influenced architecture, and in turn, human actions. Providing evidence that illustrates how this story has played out around the world and over and over again would seem to close the gap between the east and the west; between the north and the south, between high-style and vernacular.
It also meets the needs of the global marketplace for architectural services, a world in which architects and architectural students are increasingly coming into contact with cultural contexts and practices that they are unfamiliar with. One function of global history that is implied by this structure is to help make what was previously thought of as foreign, exotic and even inferior, and make it familiar, ordinary and equivalent.

The danger of this approach being that one can easily fetishize the similarities and ignore important differences. In other words, in expanding the canon to the point of collapse, one runs the risk of collapsing differences in general. In the name of creating more diversity, what we find is more of the same.

Thus, the question at hand is not if expanding the canon is good or bad. The question is what are the unintended consequences of going global? And, what other ways are there to do global history?

\section{NEW MODE}

Which brings us to Buenos Aires and the Bank of London and South America. It was commissioned by the London based and Lloyd's owned institution in 1960. It broke ground in 1962 and was completed in 1966. Clorindo Testa (working as a consultant to the firm SERPA) was its designer. ${ }^{4}$ These facts where documented and illustrated in the architectural press around the world. ${ }^{5}$ Then, in the north, silence, for 30 years. It was reintroduced to the architectural public in an exhibition and essay at the AA and in the AA Files respectively in $1997 .{ }^{6}$ This was followed by a book on Testa in 2000. Peter Cook wrote about 


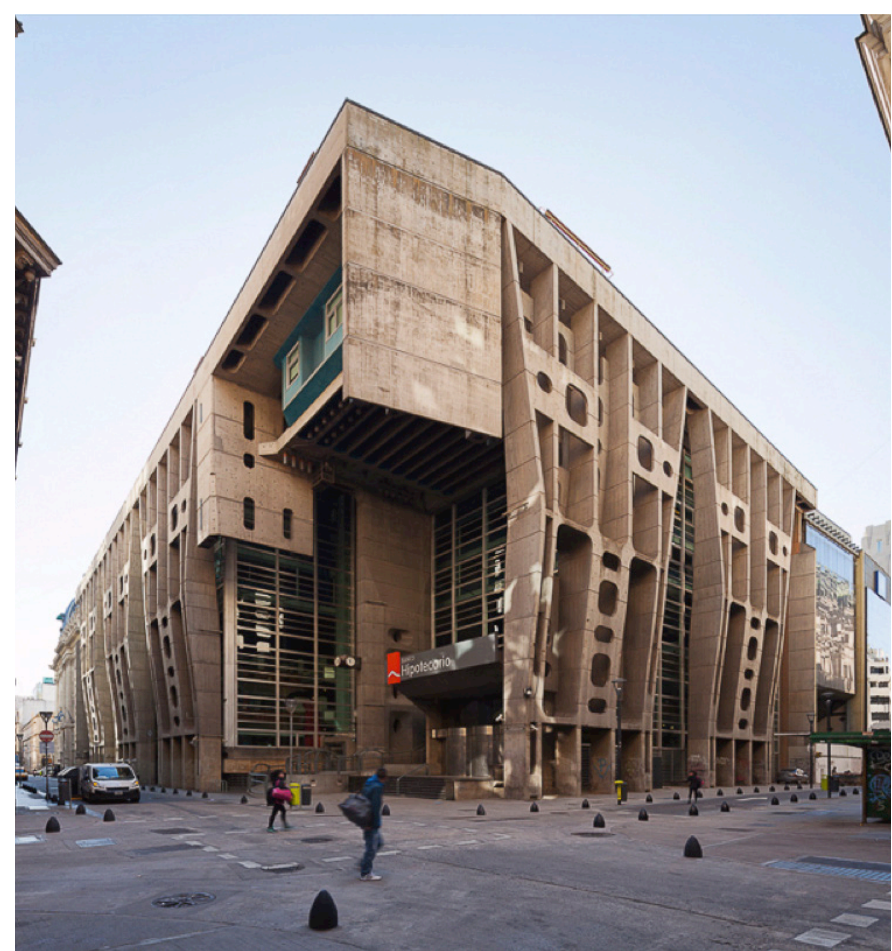

Figure 2: Bank of London and South America, Clorindo Testa \& SERPA, Buenos Aires, 1960-1966.

the building in 2001 and a book length study of it appeared in 2012. Finally, it was included in MoMA's 2015 show Latin American Under Construction. $^{7}$

It fits nicely into the GAHTC's narrative of exchange. It was literally created to help increase trade between Argentina and Great Britain. ${ }^{8}$ One could easily read its innovative forms as an attempt to mask architecture's conventional role as the emblem of economic control; or, its form can be understood as an example of a newer, softer means of reinforcing traditional hierarchies between the global north and south.

In this narrative the role of the Bank and its British project manager Gerald Wakeman would be highlighted. This might lead to a discussion of how the decision to replace a building designed in 1869 with this one was part of a coordinated effort by the British government to reestablish its economic ties with Argentina in the aftermath of WWII. ${ }^{9}$ The project's presence in the British Press would also be emphasized, as would its strong influence on the Archigram group and later on the Hi-Tech movement. ${ }^{10}$

Such influences would help illustrate how the "soft-power" of culture and media helped the "global north" maintain its influence in the post-colonial world, and how, even if one admired the ingenuity of its architects, in the end, it was an icon of traditional power rather than a challenge to it. Either way, architecture is put in the service of economic power-a familiar story.

Alternatively, within the NAAB framework, one can place it in local and regional histories of architecture (as it is clearly not vernacular or indigenous). One might compare and contrast it to the Beaux-Arts buildings in Buenos Aires and to other post-WW II modern buildings in Latin America. Testa would be compared to architects like Niermeyer, Dieste and Bo Bardi. This analysis would also highlight the influence of Claude Perret, Le Corbusier and Pier Luigi Nervi on modern Argentine architecture. ${ }^{11}$ These references could lead one to the conclusion that its design is an interesting adaptation of trends happening elsewhere in the world. One might even conclude from this line of investigation that the building isn't "Argentinian" at all, but just another immigrant from Europe. In other words, it is a foreign object.

\section{NEW MODEL}

Such conclusions would ignore the qualities found in the building itself. What mode of historical analysis would investigate and take seriously these forms and where they came from without isolating or fetishizing them? The building is too good to be ignored, but how does one historically account for its quality?

I would propose a method that looks at a project's form (its shape, spaces and surfaces) as a means for revealing the historically determined differences and similarities between and across objects, cultures, climatic zones and temporal eras. In this mode of analysis architectural form is not a historical effect, it is a historiographic device. One starts with form in order to end up with an historical narrative.

This position does not seek to reinstate a narrow canon or timeless typologies. It but it does accept the argument that some architectural objects are better, not just more representative of a culture's "political, economic, social, ecological, and technological factors," and that such quality is not in and of itself important, but is a productive way of engaging and understand the culture that produced it.

Which brings us back to Buenos Aires, where instead of positioning the BoLSA as an Argentinian or Latin American translation of European modernism, or as a pawn in the game of global capitalism, it will be compared to other contemporary banks, and evaluated as a potential member of the brutalist and megastructure families. By focusing on these types and sensibilities, it will be seen that far from belonging to any one type or genre, it has many points of origin, many destinations, and many homelands. It is cosmopolitan, it is from a specific place, but it is at home in the world. As such, it is able to tell different many tales simultaneously.

A formal-typological analysis might begin with a comparison of it and the building it replaced - a large, central hall, neo-classical buildng built in 1869s. It would also be compared to the many monumental buildings in its neighborhood, as well as to other modern banks built around the world since WWII. Such a line of inquiry would ask: in what ways is it typical or atypical of the multiple spatial and temporal contexts it belonged to? Already, such questions reveal that the project belongs to a variety of contexts, not just one.

Like its predecessor (and its neighboring National Bank of Argentina), Testa's building is organized around a large, tall, open space. The section shows a central area that is completely open from the ground level to the roof. In both the old and new building this effect was 


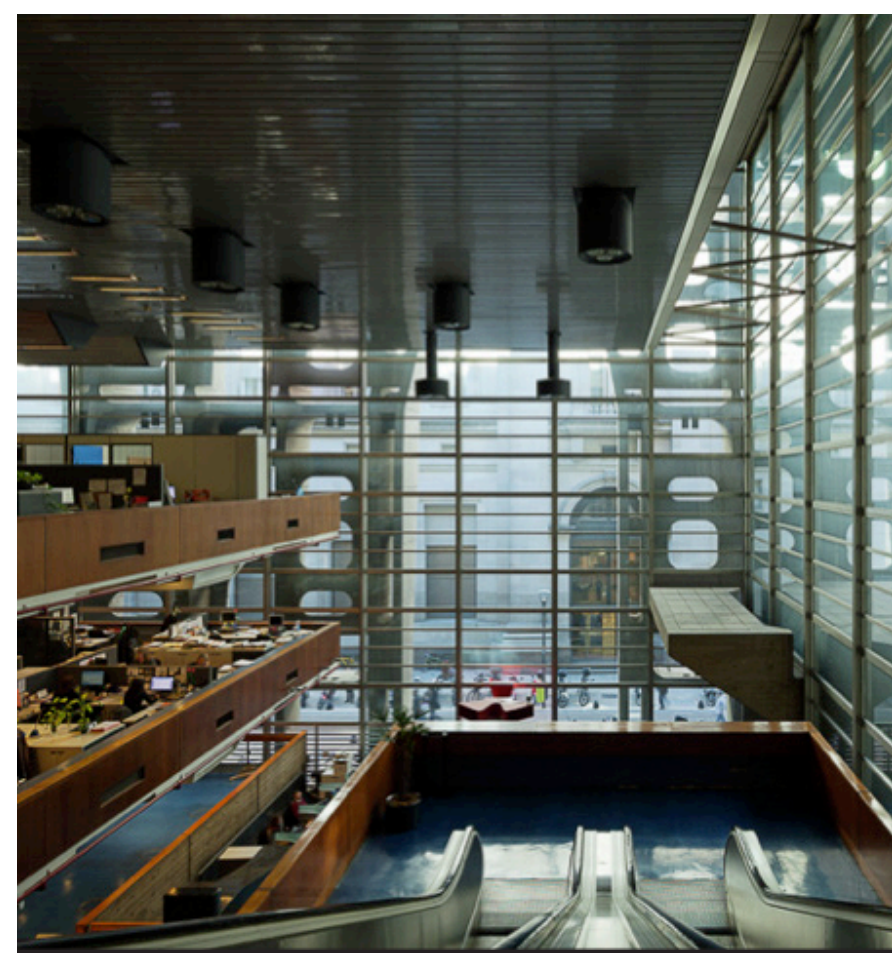

Figure 3: Bank of London and South America, Banking Hall, Clorindo Testa \& SERPA, Buenos Aires, 1960-1966.

made possible by a technologically sophisticated roof structure (the former in metal, the latter in concrete).

Without the memory of the original bank or its neighbor, this grand space would seem somewhat anachronistic. Such monumental spaces were common for 19th and early 20th century banks but less so for those built in the 1950s and 60s, for example, SOM's steel and glass designs for Manufacturers' Trust or Chase Manhattan banks in New York.

In terms of its neighborhood, its concrete and glass exterior projects a radical image onto the street. The unique, curved concrete piers sit in front of large expanses of glass on the north and west sides. In an obvious riff on the Buenos Aires version of the chamfered corner building, here the entry is located in a deep negative space set well back from the street. Despite this atypical void, and the lack of a chamfer, the tradition of holding the corner is achieved by the suspending of a concrete curtain from the roof above. As with the inside, conventions are upheld but updated.

As for its relationship to contemporary (i.e. modernist) banks, it certainly is less transparent than SOM's and Mies' well-known all-glass examples of the period. In fact, the monumental presence of its concrete piers gives it a heavy feel, which is another nod to the heavy, colonnaded buildings nearby. However, their fan-like tapered shape and large filleted wholes also exposes the transparent glass curtain wall behind them. The overall sensibility is a paradoxical one of permeable monumentality, an effect that alludes to both its neighbors and to banks in New York City.
The juxtaposition of a massive concrete structure with a glass curtain wall reveals the project's debt to both Le Corbusier and to Mies. The architects stressed that their innovative roof structure was an interpretation of Mies' suspended clear span roof at Crown Hall. However, instead of Mies' almost invisible vertical columns, here the roof is supported by the aforementioned sculptural "fans" on the exterior, and the massive piers on the inside (which also house the stairs and elevators). The latter, along with the seemingly floating floors, produce a space that is column free, but by no means empty. ${ }^{12}$

All of these concrete elements (the piers, the cores and the floors) recall the massiveness of Le Corbusier post war work. However, modern concrete buildings in Argentina pre-date the war. That tradition started at the turn of the 19th century. The partners at SERPA had built a number of dynamic projects in concrete before tackling the bank. And, unlike Corb's work of the 40s and 50s, the concrete in their work anything but brut. ${ }^{13}$

The Bank is especially refined in terms of its shapes and surfaces. Plastic formwork was used to create its smooth, continuous finish. This is especially true on the interior, where the soffits, ceilings, and stairs appear to be at once hand carved and meticulously machined; a combination that that recalls Kahn's Salk Center of a few years later. This craftsmanship reveals a generous budget, an artist's hand, but also the skill of a concrete industry that was well developed in Argentina by the 1960 s. While its design was related to the work of European masters and immigrants, its form was also a function of a local tradition.

While the exoskeleton provided some shade from the hot Argentine sun, the high budget and a commitment to technological solutions provided for a mechanical system that produced a curtain of cool air along the perimeter wall. There was also a sophisticated electrical system that allowed new computer technologies to process information from its location in the basement. ${ }^{14}$

Both the high level of craftsmanship and the integration of new technologies (the lighting coves are perhaps the best combination of the two) undermine the reading of the building as Brutalist. While a quick glance suggests this affinity, a closer one undermines it. It is not bloody-minded; this is not "rough poetry;" it is intricate, lyrical poem. This is not Chandigar, it is La Jolla.

A similar thing could be said about its association with mega-structures soon to be built in the UK and Japan. The external piers are symmetrical and repeated, but they do not belong to an infinite grid. In fact, they only appear on two sides. The floating and hanging floors one encounters on the inside - the bottom two supported from below and the top ones suspended from the ceiling - do give the impression of their belonging to a kit of parts, but they are locked in not plugged in. The building is flexible, not reconfigurable. It is an object, not a system.

A study of the BoLSA plans reveals the meandering nature of the counters, which create a perimeter that accommodate 133 teller locations. Both the curves and the number of stations seem extreme. 


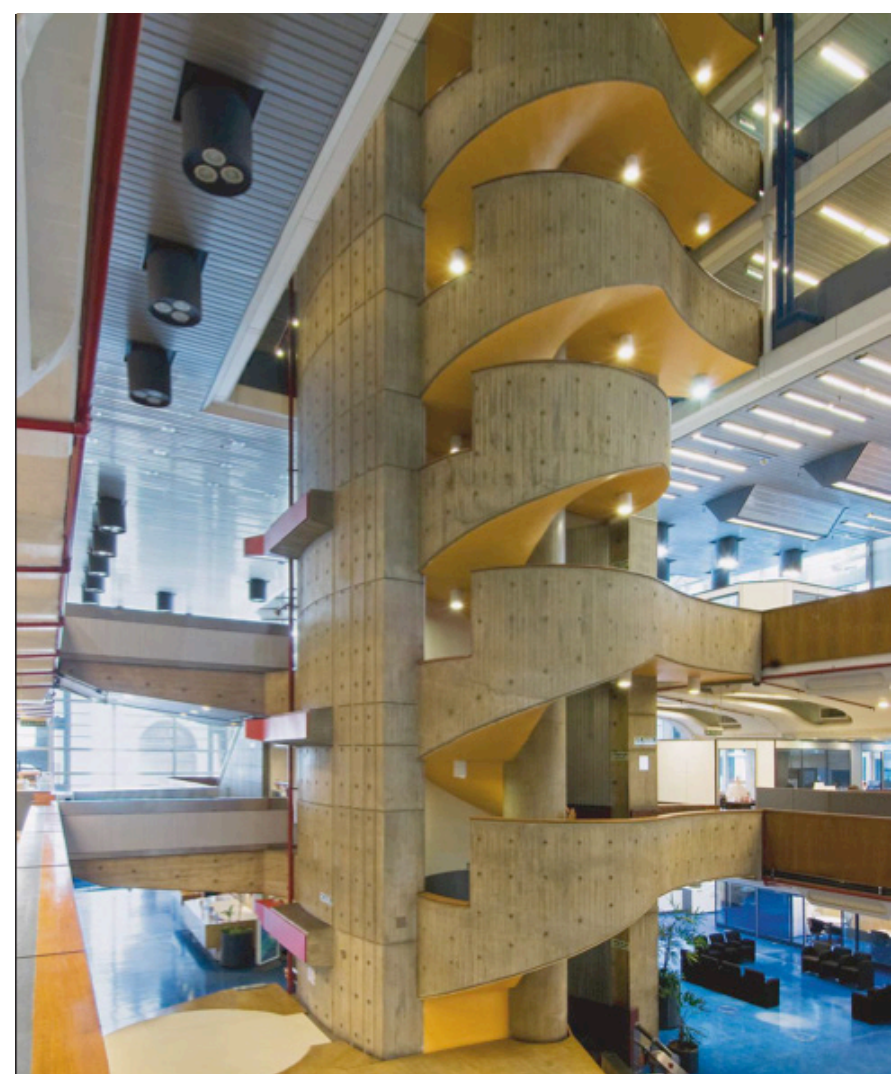

[07 Figure Number and Caption] Figure 4: Bank of London and South America, Banking Hall, Clorindo Testa \& SERPA, Buenos Aires, 1960-1966.

However, the increased linear feet the curves provide is necessary to accommodate the local practice of paying bills with cash rather than checks. In other words, the forms are there to accommodate a local practice.

\section{CONCLUSION}

In short, while alluding to many modern types and tropes, the building doesn't align with any one. There are important overlaps with local convention as well, but never a perfect one. The result is a complex combination, not a confused one. Confusion only comes when one tries to get it to conform to one type or genealogy. It is at once disglobal and dislocal. Its foreign associations prevent it from being a truly local specimen, and its local allusions prevent it from being a purely global one. Thus, it doesn't easily fit into the narratives of either the NAAB's or the GAHTC's models.

One might want to call this kind of work "critical regionalism" or "appropriate modernism." However, as the Argentine critic and historian Jorge Leirnur has pointed out, this framing always assumes the presence of a universal (western/northern) version of modernity; a state that those in the global east and south are always "outside" of, yet they are obliged to respond to. ${ }^{15}$ Within this logic the BoLSA could never be truly South American nor modern. As we have seen, it doesn't belong to a single type either. This is not its weakness. This is its strength. It is plural. By itself it embodies a variety of "parallel and divergent histories of architecture and the cultural norms of a [specific] ... local [and global] ... setting in terms of [its] political, economic, social, ecological, and technological factors."

As such, it would sit well in a yet to be composed canon made up of similarly complex, contradictory and alluring objects. Such a canon would focus on the obstinate aspect of objects. This emphasis doesn't fetishize form or isolate architecture. Rather, it uses it to identify and establish the important differences and similarities between the literal and abstract contexts like nations, cities, eras, buildings and people, that architectural objects exist it. Form is what creates these historical relationships; it is not simply the result of them.

These relationships are present in the thing itself and its relationship to other things found both near and far away from it. It is not isolated or autonomous. One must examine other architectural artifacts and documents that belong to its type(s). Its form is not enough to provide a complete history, but it is enough to get one looking in the right places. Looking at form first forces one to see where a work of architecture literally does and doesn't conform with established examples and identifies what requires further explanation.

As Sigfried Giedion suggested long ago, while architectural motifs, styles and types emerge from a specific place and time, soon after they appear they are free to inform other objects and typologies in other times and places. Tracking where they go, what they look like, who uses them, and what they do when they get there is the job of historians, teachers and students of architecture. Doing so requires asking a simple question: Where does form come from? It is surprising what follows from that humble query.

\section{ENDNOTES}

1. National Architectural Accreditation Board (NAAB), 2014 Conditions for Accreditation (Washington, D.C.: 2014), accessed via http://www.naab.org/accreditation/home.

2. National Architectural Accreditation Board (NAAB), 2009 Conditions for Accreditation, (Washington, D.C.: 2014), accessed via http://www.naab.org/ accreditation/home.

3. Mark M. Jarzombek, Vikramaditya Prakash, Francis D. K. Ching, A Global History of Architecture 2nd eds. (New York: Wiley, 2010).

4. Jorge Francisco Liernur, "The Bank of London and South America Head Office: Buenos Aires, 1960-1966," AA Files 34 (Autumn 1997): 24-44.Jorge Francisco Liernur, "Polysemy: Rereading the Readings of BLAS," in The O'Neil Ford Monograph Series, Volumne 4 - Banco de Londres y America del Sud: SEPRA and Colindo Testa, Manuel Cuadra and Wilfried Wang eds (New York: D.A.P, 2012); Manuel Cuadra, Clorindo Testa, Architect (Rotterdam: NAi Press, 2000).

5. "Bank Headquarters in Buenos Aires," The Architectural Review 113 (Februrary 1963): 122-124; "Bank of South London \& South America, Buenos Aires," Architectural Design 37 (1967): 40-48; Liernur, "Polysymy ..." documents it publication in the South American and European press.

6. Liernur, "The Bank of London and South America ..." op cit.

7. Barry Bergdoll, Carlos Eduardo Comas, Jorge Francisco Liernur, Patricio del Real eds., Latin America Under Construction: 1955-1980 (New York: MoMA, 2015).

8. Liernur, "The Bank of London and South America ..." op cit.

9. Ibid., 24-25, 28-29.

10. Peter Cook, "Clorindo Testa's Bank of London and South America, Buenos Aires," Architectural Design 71, No. 5 (2001): 44-49.

11. Liernur, "The Bank of London ...," 30.

12. Ibid.

13. Liernur, "Polysymy ..." op cit.

14. Liernur, "The Bank of London ...," 26.

15. Jorge Francisco Liernur, "For a Latin American Criticism of Contemporary Architecture," Harvard Design Magazine 34 (2011): 14-15. 